\title{
A MATERNIDADE POLIITICA EM HIBISCO ROXO, DE CHIMAMANDA ADICHIE
}

\author{
POLITICAL MOTHERHOOD IN PURPLE HIBISCUS, BY CHIMAMANDA ADICHIE
}

\begin{abstract}
RESUMO
O presente artigo se centra no estudo do gênero e da maternidade como categorias políticas diante do sujeito feminino pertencente à Nigéria, transpostas no romance Hibisco Roxo, de Chimamanda Ngozi Adichie. O corpus desta pesquisa apresenta narrativas que inscrevem o feminino como sujeitos tangenciados pela cultura patriarcal e que subvertem os lugares impostos de silenciamento. Teóricas como Amadiume (2015), Bibi Bakare-Yusuf (2003) e Amina Mama (2013) foram trazidas para o estudo, destacando a necessidade de se entender o gênero como uma categoria que perpassa as experiências coloniais e pós-coloniais na África. Assim, observamos a maternidade pelo viés político de análise, como debatida por Mary O’Brien (2007) e Andrea O'Reilly (2007) nos estudos feministas, atuando como um lugar de força e resistência de mulheres entre si, capaz de gerar modificações nas gerações que se seguem, questionando as narrativas históricas e seus lugares de protagonização e poder.
\end{abstract}

Palavras-chave: Maternidade política. Chimamanda Adichie. Literatura Nigeriana.

\section{ABSTRACT}

This article focuses on the study of gender and motherhood as political categories before the female subject belonging to Nigeria, transposed in the novel Purple Hibiscus, by Chimamanda Ngozi Adichie. The corpus of this research presents narratives which inscribe the feminine as subjects touched by the patriarchal culture and that subvert the imposed places of silencing. Theorists such as Amadiume (2015), Bibi Bakare-Yusuf (2003) and Amina Mama (2013) were brought to the study, highlighting the need to understand gender as a category that permeates colonial and post-colonial experiences in Africa. Thus, we observe motherhood through the political bias of analysis, as debated by Mary O'Brien (2007), and Andrea O'Reilly (2007) in feminist studies, acting as a place of strength and resistance among women, capable of generating changes in the generations that follow, questioning the historical narratives, and their places of protagonism and power.

Keywords: Political motherhood. Chimamanda Adichie. Nigerian literature.

Ana Ximenes Gomes de Oliveira

Doutora em Letras, UFPB, Brasil. E-mail: ximeneso6@gmail.com

Sávio Roberto Fonseca de Freitas

Doutor em Letras, UFPB, Brasil. E-mail: savioroberto1978@yahoo.com.br 


\section{Primeiras Colocações}

As representações da categoria da maternidade política na cultura nigeriana a partir do viés da escritura no feminino no romance de Chimamanda Adichie trazem questionamentos e estudos sobre noções conceituais do matriarcado e da matrilinearidade presentes historicamente. $\mathrm{O}$ matriarcado posto é problematizado como uma estrutura de poder político enquanto estrutura social, trazendo como noção basilar o olhar de pesquisadoras e escritoras africanas que ressaltam tais questões sobre a condição feminina, tanto na literatura ficcional como na críticoteórica.

Helen Chukwuma (2006) apresenta como característica recorrente na literatura de autoria feminina nigeriana, da segunda metade do século XX à contemporaneidade, a jornada, a ruptura e afastamento das personagens principais das suas casas e/ou matrimônio para traçar caminhos alternativos para sobrevivência liberta. Tal jornada não implica necessariamente em um abandono ou mesmo um afastamento de seus filhos e filhas, mas sim de um lugar de ocupação que não seria mais possível estar. A partir desse pensamento, coloco a maternidade política como, também, uma recorrência de escrita da autora aqui estudada, que dialoga com a jornada traçada dessas mulheres-personagens, construindo libertações.

A categoria que escolhemos tratar aqui constitui uma categoria não-oficial da sociedade e da organização de mulheres que nasce paralela à estrutura política, majoritariamente patriarcal, mas que se fortalece entre um ciclo de mulheres com o intuito de fortalecimento e mudança, tendo o maternar e o cuidar como um ato político de esperança para modificar a cultura.

São muitas as literaturas de autoria feminina, na contemporaneidade, que exploram a temática da maternidade em contextos nigerianos pela perspectiva do questionamento às esferas sociais. Chimamanda Adichie traz esta temática como um dos eixos necessários para a transformação da condição feminina de opressão e silenciamento. O intuito de discussão deste estudo nos trará uma base para a análise da maternidade política no romance Hibisco roxo, propondo um viés emancipatório do corpo feminino e sua vivência materna, como nos mostra a autora, difundindo ferramentas para um reposicionamento dos sujeitos através da categoria da voz como principal força de resistência.

De tal modo, entender como é estabelecida a representação e a função materna no ambiente da cultura e sociedade é o primeiro passo para a análise de como isso é posto como uma categoria de embate e dominação nas narrativas de mulheres que militam contra este posicionamento de aprisionamento do sujeito feminino e de sua fertilidade. É através da literatura que estas autoras difundem as simbolizações de suas nações.

O livro Maternal Theory: Essential Readings, organizado por Andrea O'Reilly, reúne textos de importantes teóricas nos estudos sobre maternidade no Ocidente. No capítulo intitulado “The Dialectics of Reproduction”, Mary O’Brien 
(2007) ressalta de forma basilar, epistemologicamente, que as necessidades ditas naturais e biológicas do ser humano, como a morte, a sexualidade e a fome, foram teorizadas filosoficamente para o entendimento e reflexão social. Porém, o nascimento foi dado como algo posto para o conhecimento humano, reservandose a uma teorização focadamente teológica, mas longe de uma atenção ontológica enquanto perspectiva intelectual. $\mathrm{O}$ perigo deste feito é o preenchimento dessa categoria com um masculino (paternidade) divinizado e um feminino (maternidade) sob um prisma de passividade.

A maternidade apresentada dentro de uma estrutura patriarcal foi fortemente debatida e destacada nos estudos feministas e culturais das últimas décadas, apontada muitas vezes como algo compulsório e impositivo. Considerando-se o território e a preocupação de uma localização para o apontamento dessa maternidade como instituição modeladora, esta categoria foi e é questionada e desmitificada para se reconhecer onde está o feminino e a subjetividade das mulheres para além do status materno.

Contudo, propomos aqui uma trajetória de reflexão que também busca um reencontro com essa categoria, desconstruindo-a de sua estrutura de produto de Estado e de sistema político-social. Uma maternidade política que aqui buscamos observar caminha na linha de raciocínio que encontra, nessa instância do feminino, um lugar de voz e posição de sujeito que resiste e se solidariza com outras mulheres, construindo uma propagação de discursos próprios positivos. Andrea O'Reilly (2007) aponta que foi a partir dos estudos de Adrienne Rich que a maternidade foi ressaltada pelo viés do empoderamento no continente americano e europeu, não sendo mais essencialmente apontada como uma categoria opressiva. A autora nos mostra que ainda temos poucos escritos sobre uma maternidade feminista, considerando toda a trajetória de estudos sobre maternidade patriarcal.

O'Reilly (2007) disserta sobre a aproximação entre uma teoria da maternidade e o feminismo, destacando que a análise ideológica pode ser feita mesmo sem uma adesão direta a uma política feminista. Assim, a autora em estudo se encaixa nestes dois espaços. Chimamanda Adichie assume uma identidade ideológica feminista em sua criação crítica e literária, propondo um lugar de militância pelas vidas das mulheres e sobre suas histórias. Chimamanda constrói discursos de oposição ao sistema patriarcal em relação ao controle da reprodução, do corpo e da individualidade feminina.

Minha bisavó, pelas histórias que ouvi, era feminista. Ela fugiu da casa do sujeito com quem não queria se casar e se casou com o homem que escolheu. Ela resistiu, protestou, falou alto quando se viu privada de espaço e acesso por ser do sexo feminino. Ela não conhecia a palavra "feminista". Mas nem por isso ela não era uma. Mais mulheres deveriam reivindicar essa palavra (ADICHIE, 2015, p. 49). 
A maternidade política dentro desta perspectiva de empoderamento possibilita uma transformação político-social, assumindo um lugar de ativismo capaz de ressignificar a educação de crianças e da sociedade, o que traz uma estrutura reorganizada que envolve a comunidade diante das responsabilidades de criação com base na igualdade nas relações de gênero (O’REILLY, 2007).

A luta por uma estrutura mais igualitária necessita estar atenta, também, aos outros processos de binarismos que precisam ser rompidos, como o racismo, o classismo, entre outros, que ainda apontam para um longo caminho a ser percorrido dentro do processo crítico e autocrítico dos movimentos de mulheres. Assim, considerando as especificidades dos lugares de fala apresentados, essa perspectiva de maternidade corrobora ideologicamente com nossa proposta de leitura de uma maternidade política na literatura de Chimamanda Adichie.

Observar a noção de cultura a partir de sua capacidade e atividade constante de mutação afasta os sujeitos e suas relações de um determinismo fixo que se relaciona com a tradição e a modernidade, dialogando com diversos sujeitos de territórios distintos, como expõe Bakare-Yusuf (2003, p. o1): "A partir desta perspectiva, 'cultura' e 'tradição' podem ser vistas como um projeto inacabado que está continuamente sendo transformado pelos agentes culturais”. Esse lugar de tensionar uma noção fixa de cultura é constantemente visto na construção de personagens femininas transgressoras nas narrativas de Chimamanda Adichie, como as personagens Beatrice e Ifeoma do romance Hibisco Roxo.

Bibi Bakare-Yusuf ainda destaca que, quando para teóricas africanas como Amadiume, Oyewumé e Acholonu, "enfatizam os poderes das mulheres africanas sob a rubrica da maternidade", esta é vista "para constituir o núcleo simbólico de uma poderosa posição de sujeito do sexo feminino, que contesta o que elas veem como visão feminista ocidental da perda e falta de poder social e simbólico das mulheres" (2003, p. 6).

Constatamos com a escrita de Adichie que a maternidade está presente na fala e nos escritos de mulheres como uma questão latente que transcende realizações físicas e/ou subjetivas do feminino, constituindo, assim, uma categoria basilar para as localizações das mulheres como sujeitos políticos e sociais. Na expressão literária da autora, observamos a presença tanto das relações de gênero, enquanto estrutura, como de uma maternidade observada por um viés político.

\section{A maternidade política em Hibisco roxo}

O romance Hibisco roxo, de Chimamanda N. Adichie, é o primeiro romance da autora, publicado no Brasil em 2011, que conta uma história na perspectiva de uma protagonista de quinze anos, ambientada no território nigeriano, na cidade de Enugu. $\mathrm{O}$ enredo se estrutura com a contextualização político-social de um golpe militar no país. O foco narrativo da obra se centra em primeira pessoa, sendo o 
romance dividido em quatro partes, intituladas: "Quebrando deuses: Domingo de Ramos", "Falando com nossos espíritos: Antes do Domingo de Ramos", "Os pedaços de deuses: Após o Domingo de Ramos" e "Um silêncio diferente: O presente".

Na primeira parte temos o contexto familiar e social desse núcleo central que guia a obra interligando questões políticas, culturais, socias e identitárias do contexto nigeriano no romance. Kambili Achike, narradora-personagem, é filha de Beatrice e Eugene e possui um irmão mais velho chamado Chukwuka, mas conhecido desde a infância com o apelido de Jaja. Os dois adolescentes se apresentam inicialmente no romance em conflito com sua educação religiosa e das estruturas de poder, assim como do poder do gênero, no ambiente da família. A cena que inaugura a narrativa apresenta a negação da comunhão na missa do Domingo de Ramos pelo irmão da protagonista, localizando esta negação como uma relação metafórica do questionamento às imposições de poder e às transgressões correlatas ao longo da história dessa família. Jaja se nega ao recebimento da hóstia e, com isso, inicia na narrativa a quebra de estruturas fixadas impositivamente pela posição de poder do patriarca Eugene e pela representação da Igreja como poder supremo. Com isso, toda a estrutura identitária do núcleo central da narrativa é reestruturada, criando uma concepção de renascimento e reorganização de voz.

O tempo que estrutura o romance é organizado de forma intercalada em que traz como início a ação de tensão em que os personagens começam a assumir uma posição de deslocamento de lugares de silêncio e aceitação às imposições de poder. Essa ruptura gerada no núcleo central da obra é iniciada pelo personagem irmão da protagonista, que quebra uma prática ritualística para a religião católica referente ao Domingo de Ramos, o recebimento da comunhão. Jaja é agente fundamental da primeira parte do romance, o que mostra tal quebra, presente no título da primeira parte, como uma referência tanto aos valores religiosos e culturais da família quanto aos papeis que os membros desta família desempenham, sendo rasurados pela ação de negação da eucaristia pelo adolescente.

As agressões que a personagem Beatrice vivencia são silenciadas internamente por um discurso de aceitação devido, também, à forma como seu marido se utiliza de valores religiosos presentes na trama. No momento de enfrentamento de Jaja ao seu Pai, Eugene, a estante da sala que continha as estatuetas de Beatrice é atingida, quebrando as suas bailarinas de cerâmicas. Essas estatuetas eram limpas e cuidadas pela personagem sempre que esta sofria os espancamentos de seu marido, como é descrito pela narradora:

Anos antes, quando eu ainda não entendia, eu me perguntava por que ela limpava as estatuetas sempre depois de ouvir aquele som vindo do quarto deles, um som que parecia ser de alguma coisa batendo na porta pelo lado de dentro. [...] Eu descia e a via parada ao lado da estante de vidro com um pano de prato encharcado de água e sabão. [...] Da última vez, há apenas duas semanas, quando 
seu olho inchado ainda estava da cor preto-arroxeada de um abacate maduro demais, Mama rearrumava as estatuetas depois de limpá-las (ADICHIE, 2011, p. 17).

Tem-se, assim, com a negação da hóstia por Jaja, a quebra das estatuetas de cerâmica, uma construção simbólica que participa profeticamente no enredo, visto que as bailarinas aparecem como a única coisa pertencente à Beatrice, intimamente, e que servia como uma ação de fuga depois da tristeza e da violência sofrida. Tudo a partir deste momento da narrativa é tocado, trazendo o espaço da casa como uma analogia ao espaço do contexto histórico na obra que vivencia um golpe político. Kambili nos mostra que: "A rebeldia de Jaja era como os hibiscos roxos experimentais de tia Ifeoma: rara, com cheiro suave da liberdade, uma liberdade diferente daquela que a multidão, brandindo folhas verdes, pediu na Government Square após o golpe" (ADICHIE, 2011, p. 22).

Ainda no primeiro capítulo, após o enfrentamento de Jaja ao seu pai Eugene, negando o recebimento da comunhão cristã, a narradora mostra, de forma simbólica, que com o caos tomado internamente na família novas possibilidades de transformação ressurgem: "Mais perto da casa, os coloridos arbustos de hibiscos se esticavam e tocavam uns aos outros, como se estivessem trocando pétalas." (ADICHIE, 2012, p. 15). Aqui, tem-se a presença de mais elementos sensoriais e imagéticos na obra, simbolizando as transformações geradas. Os hibiscos roxos trazidos da casa de Ifeoma, tia da protagonista que representa a transgressão feminina no romance de forma direta, são a representação da mudança. A narradora descreve neste trecho como eles começam a crescer e florescer, simbolizando a sororidade de resistência feminina que tomará conta do ambiente aos poucos: "Os arbustos de hibiscos roxos começavam a florescer lentamente, porém ainda era vermelha." (ibidem, p. 15). Essa simbologia irá se acentuar no desenvolvimento da obra como característica estética que apresenta o discurso de transgressão na narrativa, fortemente marcado pela personagem Ifeoma ao longo do romance e apropriado pela mãe da protagonista na sua trajetória.

Observa-se a presença da categoria da maternidade política perpassando o sujeito feminino e sua localização sociocultural no romance de Chimamanda Adichie. A narrativa desta escritora conta a história de uma família que absorveu a religião advinda da cultura do colonizador europeu e que tem como centralidade patriarcal de chefia o pai, Eugene. O personagem paterno apresenta uma postura extremamente rígida com seus filhos e com sua esposa, mantendo-os em uma estrutura que tem como base diversos tipos de violência exercida: física, psicológica, cultural, identitária e de gênero. A mãe de Kambili, Beatrice, é uma mulher que sofre com as agressões recebidas pelo marido, assim como as que este exerce sobre seus filhos.

Papa-Nnukwu, avô das crianças, demarca a representação e resistência da tradição e da cultura igbo, à qual todos os personagens do romance são pertencentes. Todavia, o patriarca Eugene, ao se converter à religião católica e à assimilação da 
cultura estrangeira, nega e repudia as práticas tradicionais exercidas e preservadas pelo seu pai, visto por ele como um pagão. Sobre esta visão diante da religião tradicional africana, Appiah mostra que: "O cristianismo é uma religião que se define pela doutrina; a heresia, o paganismo e o ateísmo, como resultado, foram em várias épocas temas centrais da reflexão cristã" (1997, p. 164).

Ifeoma, irmã de Eugene, é uma mulher que, ao mesmo tempo em que não nega suas raízes culturais e religiosas, também questiona em alguns momentos os valores da tradição em relação às relações e papeis de gênero, assim como faz diante dos preceitos católicos em embate com as práticas tradicionais. Assim, Ifeoma se localiza simbolicamente na trama no entre-lugar entre a tradição e a modernidade, reivindicando um lugar de autonomia para se posicionar como uma mulher que é agente enunciadora de sua própria vida.

Observa-se na narrativa a presença de quatro femininos centrais: a protagonista Kambili, uma adolescente que entra em conflito ao tensionar o poder exercido e representado pelo seu pai, que ocupa a centralidade discursiva e de poder na família; a mãe da protagonista, Beatrice, que mesmo sofrendo e não compactuando discursivamente com os valores impostos pelo seu marido em relação ao exercício de poder e a negação à representação da tradição, vive uma parte da narrativa sob seus comandos pontuado pelo seu silêncio, mas que no desenvolvimento da história é o mesmo silêncio que age como estrutura de rompimento, subvertendo o sofrimento diante dos ensinamentos e encorajamentos em diálogo com seus filhos; a tia Ifeoma, que ocupa o lugar da renovação, aquela que questiona lugares pré-estabelecidos tanto da tradição quanto da cultura exógena que rege a religião absolvida no seu contexto social e que apresenta a jornada a ser vivida como uma possibilidade real; e Amaka, filha de Ifeoma, que é fruto de uma maternidade transgressora e que ao se relacionar com sua prima Kambili demarca um feminino em movimento para assumir uma performance política na sociedade.

Por se tratar de um romance com o foco narrativo em primeira pessoa, tem-se a instância narrativa através dos olhos e imaginação de uma adolescenteprotagonista. Além desta, os discursos proferidos pelas mulheres que atuam na narrativa são postos em caráter ora reflexivo e criativo, ora como repostas de confronto. Kambili, ao narrar um momento em que sua tia Ifeoma entra em sua casa demonstra sua percepção diante de um sujeito de força, independente desta ser reconhecida como um discurso autorizado, representando, também, uma categoria de herança e memória:

Quando ela irrompeu na sala do segundo andar, imaginei uma orgulhosa ancestral andando quilômetros para pegar água em potes de barro feitos em casa, cuidando das crianças até que elas soubessem andar e falar, lutando em guerras com machadinhas afiadas em pedras quentes de sol. Ela enchia o cômodo todo (ADICHIE, 2011, p. 88). 
Percebe-se a descrição dessa personagem como uma rasura na própria estrutura existente de hierarquia patriarcal, deslocando a enunciação para os sujeitos femininos em articulação entre si ou em monólogo interior sobre sua perspectiva do mundo, como acontece com a narradora-personagem. Sua participação como discurso direto sempre se diferencia entre o discurso oculto, interno, do desejo de relatar ou se contrapor a algo com respostas, e o discurso relatado em suas falas, que se materializam em falas contidas que adquirem um crescimento na progressão do tempo da narrativa. Kambili vive em constante observação repressora, protagonizada pelo seu pai e ampliada simbolicamente para o discurso religioso de uma vigília constante, que lhe acompanha e modula seu processo de subjetivação.

Chimamanda Adichie, no seu livro intitulado Para educar crianças feministas: um manifesto, conta que em conversa com um amigo chamado Ikenga, o mesmo lhe contou que na sua família há um reconhecimento social de que seu pai comanda a casa e a família, porém, nos bastidores quem exerce poder, quem manda, é sua mãe. Com isso, Adichie questiona: "Por que 'nos bastidores'? Se uma mulher tem poder, por que precisamos dissimular o fato?” (2017, p. 32-33). Considerando as necessidades de compreender de forma interseccional a localização contextual e histórico-social para pensar em vários sujeitos femininos, destacamos o que pontua a escritora nigeriana Amina Mama, que participa do livro Africana: Aportaciones para la descolonización del feminismo, ao refletir sobre as lutas femininas (e feministas):

El feminismo continúa siendo un término positivo, basado en el movimiento, y me alegro que se me identifique con él. Indica un rechazo de la opresión, la lucha de la liberación de las mujeres de toda forma de opresión, interna, externa, psicológica y emocional, socioeconómica, política y filosófica. Me gusta el término porque me identifica con una comunidad de mujeres radicales y seguras de ellas mismas, muchas de las cuales admiro, como personas y por lo que han contribuido a desarrollar. Estos referentes son mujeres africanas, asiáticas, latinoamericanas, del Oriente Medio, de Europa y de América del Norte, de todos los colores y tendencias, del pasado y del presente. (2013, p. 9-10). ${ }^{1}$

Na narrativa de Chimamanda Adichie, vemos que os papéis de gênero aparecem notórios para refletir a própria concepção de poder, visto que na luta por uma equidade social de gênero não discutimos uma inversão do poder, mas um espaço para o posicionamento de voz entre ambos. Tal perspectiva dialoga diretamente com a construção da personagem Ifeoma.

1 "Feminismo continua a ser um termo positivo, baseado no movimento, e estou feliz por poder me identificar com isso. Indica uma rejeição da opressão, a luta pela libertação das mulheres de todas as formas de opressão, interna, externa, psicológica e emocional, socioeconômica, política e filosófica. Gosto do termo porque me identifica com uma comunidade de mulheres radicais e confiantes, muitas das quais admiro, como pessoas e pelo que contribuíram para desenvolver. Essas referências são mulheres africanas, asiáticas, latino-americanas, do Oriente Médio, europeias e norte-americanas, de todas as cores e tendências, do passado e do presente." (MAMA, 2013, p. 9-10, tradução nossa). 
Diante da configuração de uma maternidade política dentro do romance, observa-se como essa instituição opera em dois movimentos: um mecanismo que se interliga ao processo identitário e participativo do feminino nesta sociedade mostrada na obra; e um ponto de tensão e de libertação para pensar em outros sujeitos femininos que se encorajam e se renovam de geração para geração. Tal renovação é possibilitada através de uma propagação de discursos entre mulheres, que independem de um discurso oficial vigente. Na obra, temos a personagem Beatrice que se percebe impulsionada em seu matrimônio pela necessidade de fecundação biológica como representação de pertença aos costumes:

Deus é fiel. Depois que você nasceu e eu sofri aqueles abortos, o povo da vila começou a falar. Os membros da nossa umunna até mandaram pessoas para falar com seu pai e insistir que ele tivesse filhos com outra mulher. Tantos tinham filhas disponíveis, muitas das quais formadas em universidades e tudo. Elas poderiam ter parido muitos filhos [...] (ADICHIE, 2011, p. 26).

Observa-se, com isso, a presença da maternidade que demarca a construção de um sujeito político feminino, um sujeito que se insere e é inserido na necessidade de conceber biologicamente um ser e maternar dentro da sociedade. É notório, assim, perceber como uma categoria do feminino que representa alegrias e a força geradora do gênero pode ser também uma instância de tensão quando cobrada pela sua realização, pressionando o feminino para além de suas escolhas no corpo e no tempo. Beatrice menciona os abortos vividos em seu casamento e estes são mostrados na narrativa ligados a uma violência física gerada pelo pai Eugene.

A partir de uma perspectiva macro do romance, a maternidade está presente no início da obra como uma categoria que é sobressaltada no corpo e na sua necessidade de ser realizada biologicamente. $\mathrm{O}$ corpo feminino fecunda e gera outro corpo, representando sua importância como uma nascente de novas gerações e possibilidades de "novas" nações em construção, carregando com si a herança identitária da memória e de seus antepassados como identidade viva. Ife Amadiume (2015), ao dissertar historicamente sobre as relações de gênero para a sociedade Nnobi, na Nigéria, relata que a partir da cerimônia de casamento até a chegada do primeiro filho de um casal, muitos rituais de fertilidade e sexualidade para o parto são realizados com a mulher (p. 74). Além disso, nessa sociedade, a autora nos diz que há uma ênfase para a característica produtora dada ao feminino, seja no âmbito da produção de subsistência ou na produção biológica da maternidade (ibidem, p. 69).

Aproximando esse relato à narrativa em questão de Hibisco roxo, nota-se a presença desse valor e singularidade ao feminino dada sua importância na sociedade. Assim, destaca-se pontos de vista questionadores nas categorias referentes à maternidade, matrimônio, liberdade, autonomia e cultura, que recaem sobre o feminino e, consequentemente, as reações deste diante da experiência vivida. Apontase, aqui, a maternidade como categoria política de construção e reconhecimento das 
mulheres e de um ponto fundamental trazido por estas como base para compreender as localizações de status nas relações de gênero.

Ife Amadiume, em seu estudo, mostra que é através da oralidade que ocorre a transmissão tanto dos costumes e valores tradicionais como das concepções das relações de gênero e do próprio gênero (2015, p. 69). Na sociedade ambientada em Hibisco roxo, apresenta-se um embate entre duas concepções, representadas por Beatrice e Ifeoma, relacionadas ao papel do gênero, sobretudo às necessidades diante do feminino sobre o casamento e a maternidade. A personagem Beatrice interroga sua cunhada dizendo: "Uma mulher com filhos e sem marido é o que?" e em resposta, Ifeoma lhe diz: "Eu. [...] Nwunye, às vezes a vida começa quando o casamento acaba" (ADICHIE, 2011, p. 83).

Esta noção de vida que Ifeoma menciona relata um conceito de independência e autonomia com a liberdade após o matrimônio. Ifeoma é a representação, apontada pela própria narradora, da coragem, da emancipação diante de uma sociedade. São duas visões de resistências que caminham por estradas distintas, mas que miram a liberdade e uma sororidade que fortalece. Nesta fala, a cunhada de Beatrice, que a chama carinhosamente de "minha esposa" em igbo, mostra para a mãe da protagonista a possibilidade de negação aos valores estabelecidos pela sociedade, tanto dos costumes da tradição como da religião católica vinda do estrangeiro. Oliveira (2015) nos diz que:

[...] as práticas religiosas devem ser entendidas como rituais de memória coletiva, de continuidade da tradição, de reafirmação do sentimento de pertença, como momento espacial e temporal de vivência, de solidariedade. [...] A religião atribui poder às pessoas, diferenciando-as dentro da própria comunidade, retrata a ordem social, modela a sociedade tanto em termos morais como funcionais, utilizando-se de símbolos religiosos [...] (p. 43).

Ifeoma traz para a narrativa uma concepção de vivência da maternidade como um florescimento constante, mesmo em situações adversas e que foram edificadas a partir do desejo e da ação. Chimamanda Adichie estrutura o ambiente que localiza essa personagem, sua casa, os deslocamentos externos pela cidade e seu espaço de trabalho (o Instituto de Estudos Africanos na Universidade de Nsuka), mostrando um envolvimento constante com uma simbologia das cores, das plantas e das flores. No momento da narrativa em que Kambili e Jaja vão para a casa de sua tia, na cidade de Nsuka, para passar um período de férias, a descrição do espaço da narrativa e suas simbologias se modificam com uma forte presença da metáfora das flores. Ao descrever o prédio em que Ifeoma reside, a narradora diz que: "Na frente dele, havia um círculo de cores vibrantes - um jardim - com uma cerca de arame farpado em volta. Rosas, hibiscos, lírios, ixoras e crótons cresciam lado a lado como uma guirlanda pintada à mão" (ADICHIE, 2011, p. 122-123). Tal ênfase na descrição das cores e flores, remetendo a uma convivência de ligação e de construção mútua, se 
mantém presente no espaço que envolve Ifeoma: "As casas pelas quais passamos tinham cercas de girassóis, e as bolinhas amarelas das flores do tamanho de uma mão aberta alegravam a folhagem" (Ibidem, p. 139), diz a narradora.

Roseiras, cajueiros, cerejeiras, mangueiras, grama seca, árvores frutíferas, nims, entre outras, participam do desenho imagético desse espaço pertencente à personagem. Na fala de Ifeoma tem-se, também, a lembrança de que aquilo que parece natural também pode ser modificado e se tornar algo positivo, como é visto na explicação dada ao sobrinho Jaja quando este se surpreende com a existência de hibiscos roxos em seu jardim: "Todo mundo tem essa reação quando vê essas flores pela primeira vez. Minha amiga Phillipa é professora de botânica. Ela fez alguns experimentos na época em que morava aqui" (ADICHIE, 2011, p. 138).

Ifeoma é descrita como uma mulher de expansão pela observação da narradora, o que constrói uma personagem mulher e mãe que mantém sozinha sua casa e família após a morte de seu marido, Ifediora, trazendo essa vivência materna como algo de fluidez, como uma instância que permite e age para que seus filhos tenham voz dentro e fora de casa: "Risadas flutuavam em minha cabeça. Palavras jorravam da boca de todos, muitas vezes sem procurar nem receber nenhuma resposta. Lá em casa só falávamos quando tínhamos algo importante a dizer, sobretudo quando estávamos sentados à mesa" (ADICHIE, 2011, p. 130), diz a narradora. Na personagem Ifeoma, a maternidade política que identificamos é notória e direta na sua ação com o mundo, uma maternidade de florescimento, uma construção e enfrentamento que se mostra no discurso que profere. No estranhamento inicial da narradora por estar diante desta configuração familiar, ela ainda destaca que: "Até então eu me sentira como se não estivesse ali, como se estivesse apenas observando uma mesa onde se podia dizer o que você quisesse, para quem quisesse, onde o ar era livre para ser respirado à vontade" (ADICHIE, 2011, p. 130).

Ifeoma nos traz uma ligação entre a tradição e a modernidade em convivência nesse ambiente de renovação, metaforicamente multicor. A chegada de seu pai, Papa-Nnukwu, para conviver um tempo em sua casa enquanto está doente, junto da presença de seus sobrinhos, Kambili e Jaja, e sempre auxiliada pelo jovem padre Amadi, demonstra essa interligação. Papa-Nnukwu firma no texto a manutenção da tradição viva através de sua oralidade e da contação de histórias sempre pedida pelas crianças: "Papa-Nnukwu, conte uma história então, como faz quando estamos em Abba” (ADICHIE, 2011, p. 169). As crianças solicitam a contação ao avô, que atende aos pedidos contando a história do jabuti e seu casco partido. Na sua contação, temse a narração de uma aldeia de animais em que as mães aceitam se sacrificar em tempos de fome para servir de alimento para seus filhotes. Entre os bichos da aldeia, tem-se o Cão que diz perder sua mãe por doença e ao final se descobre que este é alimentado por ela e pelos amigos ricos dela que estão no céu. Quando termina a história, as crianças levantam perguntas à Papa-Nnukwu sobre quem seriam estes amigos ricos no céu que alimentavam o Cão junto da sua mãe e Obiora responde: "Deviam ser os ancestrais do Cão" (ibidem, p. 172). 
Com a história narrada pelo Papa-Nnukwu, observa-se a presença da maternidade interligada à continuação da memória e sabedoria, da ancestralidade da cultura. A condição materna participa, assim, do ciclo de renovação que alimenta o (re)nascimento não só dos indivíduos, mas também da história narrada que preserva a inteligência de uma sociedade. Na narrativa em tela, Papa-Nnukwu é visto por Ifeoma, dada sua importância como representante da memória e tradição de sua cultura. A tia diz a Kambili que ele está melhorando de sua doença por interseção de Nossa Senhora (dentro da fé católica). A narradora, que foi ensinada pelo seu pai a ver seu avô como um "pagão", conta que quando interrogou sua tia sobre como isso poderia ter acontecido, ouviu que: "Papa-Nnukwu não era um pagão, mas um tradicionalista, que às vezes o que era diferente era tão bom quando o que era familiar, que quando Papa-Nnukwu fazia seu itu-nzu de manhã, sua declaração de inocência, era a mesma coisa que quando rezávamos o rosário" (ADICHIE, 2011, p. 177).

Com isso, Ifeoma nos leva para uma concepção sobre a religiosidade e crenças tradicionais de uma cultura a partir de um lugar intermediário, que compreende seu deslocamento diante de valores adquiridos como uma expansão, que não nega a memória e história a qual faz parte. Desde o momento em que Kambili e Jaja saem da casa de sua família para passar as férias em Nsuka com sua tia, a personagem Beatrice, mãe dos(as) adolescentes, é retirada momentaneamente da ação narrativa, aparecendo poucas vezes com falas em ligações telefônicas para falar com seus filhos. A representação materna durante todo esse período é concentrada na tia da protagonista, contrastando com Beatrice em seus posicionamentos subjetivos nas afirmações do meio social e com a criação no ambiente familiar da casa.

Beatrice é uma personagem em que a maternidade age através de ações que só dialogam na relação estreita entre esta personagem e seus filhos, atuando na margem do poder central de seu marido. A sublimação do confronto com o poder masculino é constante nos ambientes de convívio na casa, na igreja, nos eventos sociais e com os membros da ummuna a qual pertencem, a família tradicional na cultura igbo. Beatrice resiste ao convívio constante com a violência, buscando manter sua família. Há, assim, um movimento de plantar força para que tanto ela quanto seus filhos consigam resistir às dificuldades vividas no convívio com seu pai. A ação em Beatrice caminha ao longo do romance de forma silenciosa, de uma personagem que observa todo o exercício do poder masculino de seu marido, convivendo por vezes em lugares que se subordinam às instituições como a família e a igreja.

Como estabelecemos aqui uma conceituação da maternidade política como algo que tangencia o feminino, primeiro como uma presença que participa de seu processo de subjetivação e segundo como uma ação de construir uma resistência, tomando sua forma a partir da vivência materna de cada mulher, voltamo-nos, então, para o maternar em Beatrice como uma constituição política de ação sobre o que recai em sua vida, as expectativas suas e da sociedade, e de como isso é transformado como um lugar de poder, um lugar de ação não-oficial. A compreensão tanto do lugar da maternidade que é cobrado pelo externo, assim como da necessidade do matrimônio como validação de uma vida de sucesso para as mulheres, também 
permeia o pensamento da personagem. Contudo, diante das práticas vividas que invadem sua subjetividade através da violência em casa, seu discurso sobre tais instâncias passa a ser modificado.

Através da metáfora e simbologia das flores e das cores na narrativa, a ação materna dessas duas personagens centrais, Ifeoma e Beatrice, passa a se interligar e a construir uma tomada de consciência entre essas duas estruturas que se distinguem diante de seus posicionamentos. Há uma recorrência que caminha como uma rede de expansão simbolizada pelo caminho percorrido das flores no universo ficcional das personagens, como um prenuncio de mudanças e transgressões que atingirão o destino da história narrada. O hibisco roxo, como uma planta vista por Kambili e Jaja na casa da sua tia, é uma representação de algo que nasce a partir de uma ligação com outro(a) semelhante, gerando o novo, o diferente, transformado em algo belo. O irmão da protagonista, ao retornar para casa de seu pai em Enugu, conta para Kambili que trouxe da casa de Ifeoma alguns galhos desse hibisco para plantar em seu jardim, como conta a narradora:

Jaja ia dá-los ao jardineiro. Ainda estava na época do harmattan e a terra tinha sede, mas tia Ifeoma dissera que os galhos podiam criar raízes e crescer se fossem molhados regularmente [...]. Os olhos de Jaja brilharam quando ele falou dos hibiscos, quando os tirou da geladeira para que eu pudesse tocar os galhos frios e úmidos" (ADICHIE, 2011, p. 210).

Assim como os galhos dos hibiscos roxos passam a caminhar nos espaços da narrativa, como uma simbologia de criação autônoma, saindo do espaço pertencente à personagem Ifeoma para aquele de atuação de Beatrice, a transgressão também percorre essa mesma trajetória. A partir desse momento de retorno à casa, tanto Kambili e Jaja como Beatrice protagonizarão caminhos para liberdade. Eugene é o personagem que luta e discursa sobre a liberdade social e externa, diante de uma política autoritária em seu país, mantendo os embates travados pelo seu jornal para questionar tal situação. Nesse mesmo núcleo ficcional cujo o pai faz parte, Kambili, Beatrice e Jaja lutam por uma liberdade do sujeito a partir do espaço privado, questionando as imposições de poder do masculino que se apresenta embasado pelos valores religiosos que o patriarca da casa utiliza para estabelecer um governo autoritário na estrutura micro do espaço literário.

Diante da referida simbologia das plantas, essa estrutura de transgressão, que parte do ambiente interno e privado, transgride os muros deste espaço para criar uma conexão com o que está fora, possibilitando, assim, a circulação de suas personagens que se desprendem da submissão ao pai Eugene. O deslocamento realizado pela protagonista e seu irmão de ir até a cidade de sua tia e serem invadidos por um sentimento e uma vivência real de liberdade no mundo, de encontro com formações identitárias antes negadas de forma impositora pelo seu pai, é retornado pelas plantas, pelas cores, os galhos de hibiscos roxos que foram dados por Ifeoma 
para serem plantados na casa de Beatrice. Dessa forma, há um movimento circular da transgressão na narrativa. Fry (1957) diz que, no processo de leitura,

[...] nossa atenção se move ao mesmo tempo em duas direções. Uma direção é exterior ou centrífuga, e nela ficamos indo para fora de nossa leitura [...]. A outra direção é interna ou centrípeta, e nela tentamos determinar com as palavras o sentido da configuração verbal mais ampla que elas formam (p. 77).

Por isso, trazemos para análise a perspectiva do símbolo diante das flores e, especificamente, dos hibiscos roxos, dentro da narrativa, operando como anunciação das mudanças que ocorrem nas ações das personagens. Internamente, os deslocamentos dos hibiscos roxos e a modificação (amplitude) do seu significado, de algo voluntariamente construído pelas mãos de mulheres, está na direção centrípeta de leitura a partir da presença do signo no romance, enquanto que a transgressão e transformação atribuída na leitura extrapola o limite verbal de significação e se interliga com o discurso transgressor no entendimento do enredo em que a autora estrutura o romance. Como nos diz o autor: "Em literatura o que entretém precede ao que instrui, ou, como podemos dizer, o princípio da realidade se subordina ao princípio do prazer" (FRY, 1957, p. 79).

Chimamanda Adichie constrói uma fluência conectada com as representações sensitivas presentes no texto. Cores e imagens de florescimento estruturam uma imagem literária que contrasta com a vivência ligada à dificuldade na jornada, sobretudo, das personagens femininas. A imagem formada, assim, é aproximada à maternidade vivida e (re)construída pelas mulheres presentes no romance. Os silêncios de Beatrice diante da violência vivida atuam na narrativa como uma presença. Diante da violência que sofre no casamento com as agressões físicas e as que são destinadas aos seus filhos, a personagem não interfere verbalmente para um impedimento dos fatos. A presença do seu silêncio se torna uma lacuna, que aos poucos será preenchida também pelas intervenções discursivas de sua cunhada Ifeoma, uma mulher que questiona e discursa uma outra visão dos papeis de gênero na sociedade e na cultura. Este posicionamento de Ifeoma pode ser conferido no momento em que seu pai, Papa-Nnukwu, lhe diz: "Meu espírito vai interceder em seu favor, para que Chukwu mande um bom homem para tomar conta de você e das crianças", e em resposta Ifeoma profere: "Seu espírito que peça a Chukwu para acelerar minha promoção a professora sênior, é só isso que eu quero” (ADICHIE, 2011, p. 92).

Compreendemos, com isso, a condição feminina interligada pela condição materna como algo que pode gerar frustrações e tensões no feminino pela possível (não) realização, assim como também gera a força que questiona um lugar de violência e expectativas sociais, mostrando-se independente para construir suas decisões e possibilidades de caminhos diversos. Essa concepção está presente no romance Hibisco roxo através da conexão entre as duas personagens mulheres e mães 
fundamentais na narrativa. Pensar o corpo feminino como um lugar de sobreposição é pensar nas construções e ferramentas tidas nas diversas formas do patriarcado que são questionadas por mulheres transgressoras.

Após o espancamento sofrido pela protagonista, cometido pelo seu pai quando encontra uma pintura do retrato de Papa-Nnukwu no quarto da adolescente, Beatrice recebe um encorajamento de Ifeoma para retraçar seu destino, abandonando seu marido e a condição de submissão vivida: "Quero que Kambili e Jaja fiquem conosco, pelo menos até a Páscoa. Faça uma mala você também e venha para Nsuka. Vai ser mais fácil para você ir embora quando as crianças não estiverem lá" (ADICHIE, 2011, p. 226). Observa-se que a estrutura que mantém Beatrice sob o poder de Eugene é a estrutura da família e o cuidado e preservação da vida de seu filho e filha. Ifeoma apresenta, assim, um outro lugar para viver a maternidade, um lugar que, mesmo abandonando a casa como estrutura fixa para a sociedade, tem-se o nascimento de uma outra casa em solidariedade com a representação da mãe tida em Ifeoma.

Além da estrutura da maternidade vivida nas duas personagens citadas, Chimamanda traz para a narrativa também as interrupções maternas geradas pela violência. Beatrice tem, no período de conflito em sua família, algumas gestações que aparecem no silêncio e são findadas por momentos de agressão física de seu marido, gerando abortos consecutivos: "Sabe aquela mesinha onde guardamos a Bíblia da nossa casa, nne? Seu pai quebrou-a na minha barriga. [...] Meu médico disse que não pôde fazer nada para salvá-lo" (ADICHIE, 2011, p. 262), disse Beatrice ao fugir para a casa de Ifeoma enquanto seus filhos estavam lá. Quando sua cunhada, surpresa, lhe pergunta sobre o que disse o médico, Beatrice acrescenta: "Eu estava grávida de seis semanas. [...] Eugene não sabia. Eu ainda não tinha contado a ele, mas é verdade" (ibidem, p. 263). Assim, percebe-se como a instância materna é constantemente posta em tensão e em um lugar de força para se contrapor, como visto em Ifeoma.

Quando partimos para a penúltima parte do romance, intitulada "Os pedaços de deuses: Após o domingo de Ramos", temos os resquícios do desmoronamento causado pela ruptura com a família e os questionamentos sobre as práticas das personagens na religião católica. A narradora no início do romance mostra como o florescimento começa a acontecer após seu irmão ter negado receber a hóstia na missa do Domingo de Ramos, simbolizando no florescimento dos hibiscos roxos em seu jardim. Esta celebração ocorre após sua temporada na casa de Ifeoma, fato que modificou toda a trajetória da família:

Tudo desmoronou após o Domingo de Ramos. Ventos uivantes vieram com uma chuva, arrancando algumas plumérias no jardim. Elas ficaram caídas sobre a grama, suas flores brancas e cor-de-rosa tocando o chão e as raízes à mostra com pedaços de terra oscilando no vento. [...] Até o silêncio que caiu sobre a casa foi súbito, como se o velho silêncio houvesse se rompido e tivéssemos ficado com seus pedaços afiados nas mãos (ADICHIE, 2011, p. 271). 
Assim como o confronto entre a identidade da tradição e a pertence imposta diante da religião católica, o endeusamento dado à representação paterna em Eugene também foi rompido, deixando "pedaços afiados nas mãos" como formas de se contrapor ao lugar estabelecido de conformidade. A narrativa de Hibisco roxo é estruturada em uma intercalação do tempo que se inicia com o presente, apresentando uma ação de tensão, seguindo para uma rememoração que nos explica o caminho percorrido das personagens para gerar tal ação, e continua nas duas partes finais com o desenvolvimento do enredo, voltando para um tempo linear e progressivo ao fato inicial.

A segunda parte do romance funciona, então, como uma forma de flashback. Sobre este recurso, Mendilow (1972) diz que o autor ou autora nos coloca diante da vida da protagonista para entendimento do fato inicial, apresentado em outro tempo narrativo, compreendendo uma organização lógica das ações que possibilitaram os episódios de tensão já narrados. Podemos interpretar em Hibisco roxo que o tempo predominante, devido a sua extensão na obra, é uma construção de um presente fictício em que a autora situa a protagonista na narração de toda a sucessão de eventos anteriores ao Domingo de Ramos, sendo fundamental para compreender a estruturação psicológica de ação dos personagens posteriormente. Essa observação se aproxima do que Mendilow (1972) afirma sobre a estruturação do tempo no romance apresentar esses "graus de passado": "Na maioria das vêzes o pretérito em que os eventos são narrados é transposto pelo leitor para um presente fictício, enquanto sente-se qualquer matéria expositiva como um passado em relação a esse presente" (p. 106).

Chimamanda Adichie estrutura seus personagens buscando um distanciamento a uma noção absoluta e fixa entre o bem e o mal. O personagem Eugene apresenta uma dupla característica entre o que é visto como bondade e solidariedade (para a sociedade), e a violência impositora de uma única verdade regendo o tratamento com seus familiares.

"Você sabia que Eugene paga a mensalidade escolar de mais de cem pessoas? Sabe quantas pessoas estão vivas por causa do seu irmão? " (ADICHIE, 2011, p. 264), diz Beatrice no momento em que procura alguma forma de justificativa para compreender as ações de seu marido, que estava vivendo um momento de pressão muito forte, e assim voltar para casa. Contudo, Ifeoma lhe mostra como um posicionamento solidário não pode estabelecer um espaço de dominação sobre seu corpo, que o que é visto como uma validação de invasão por fornecer um bem comum precisa ser questionado: “Quando Ifediora estava vivo, houve época, nwunye, em que a universidade passou meses sem pagar nossos salários. Ifediora e eu não tínhamos nada, mas ele nunca ergueu a mão para mim" (ibidem).

Visto o lugar social da voz feminina que segue lutando por mais espaços de atuação, sendo por vezes interdito pelo masculino como no caso contínuo de Beatrice, constrói-se ao longo da narrativa uma ocupação desse espaço através de uma voz que atua politicamente como uma força para não mais se subordinar a abandonar seus desejos e autonomia. Identifico aqui a presença de uma oralidade política discursiva, 
que estabelece possibilidades de transgressão a partir do compartilhamento sucessivo de outras formas de "ser mulher", de identidades femininas que não necessitam de um desprendimento ou abandono de suas tradições nem da experiência materna, mas que remontam outras formas de maternidade diante das experiências singulares de cada sujeito.

Diante da construção das personagens femininas e da transgressão que caminha na jornada dessas mulheres, Amaka se situa como uma renovação da personagem Ifeoma, que confirma um processo em rede de fortalecimento do feminino de geração para geração, pois questiona também o estabelecimento da religião católica em seu país como pertencente ao processo de invasão e colonização: "Os missionários brancos trouxeram seu deus para cá - disse Amaka. - Um deus da mesma cor que eles, adotado na língua deles e empacotado nas caixas que eles fabricam" (ADICHIE, 2011, p. 281). A fala da adolescente é dirigida ao padre Amadi, que não é estrangeiro e recebe a missão de migrar para a Alemanha como missionário.

Appiah, sobre as religiões tradicionais africanas, nos lembra que: "o debate filosófico sobre o status da religião tradicional tornou-se realmente central na filosofia recente justamente porque o entendimento da religião tradicional é central para as questões conceituais suscitadas pela modernização" (1997, p. 156). Assim, diante de uma percepção de doutrinação do cristianismo diante do mundo, observase, a partir da narrativa representada tanto na relação de Eugene com Papa-Nnukwu, quanto do diálogo entre Amaka e o padre Amadi, que a perspectiva cristã enquanto religião que apresenta uma verbalização de sua crença como profetização da "verdade" posiciona as religiões tradicionais no campo do simbólico, distanciandose, consequentemente, do entendimento da importância e do sistema de crenças dessas religiões: "os simbolistas só conseguem tratar os fiéis tradicionais como seguramente racionais porque negam que as pessoas tradicionalistas pretendam dizer o que dizem" (ibidem, p. 166). Com isso, o questionamento dado por Amaka atribui-se, também, à modulação sobre o pensamento nas crenças religiosas que, com o processo de colonização e a entrada de uma religião católica cristã na cultura, insere-se uma noção epistemológica que se sobrepõe à religião tradicional de um local.

As ações de Beatrice permanecem em forma lenta e silenciosa, desde sua luta para manter a família e seu reconhecimento diante da ummuna, a sua sobrevivência e o cuidado com seus filhos, até sua tomada de consciência para agir rompendo um círculo de violências dentro do matrimônio. Beatrice realiza a reviravolta na narrativa, transformando o destino de seus filhos através da morte do seu marido. Jaja, seu filho, assume o assassinato de seu pai, sendo preso por três anos. O ato de Jaja assumir a morte de seu pai para proteger sua mãe é também o rompimento de uma lógica de sacrifício atribuído ao materno. A estória contada por Papa-Nnukwu sobre os animais que, em período de fome, alimentavam-se de suas mães para sobreviver, visto que estas não se opunham ao ato para proteger seus filhos, é invertida no desfecho da narrativa em tela. Temos 
uma outra possibilidade de rompimento para a condição feminina que aponta para o futuro, reiniciando um ciclo de renascimento: "Vamos levar Jaja primeiro para Nsuka e depois vamos aos Estados Unidos visitar tia Ieofma - digo - Vamos plantar laranjeiras novas em Abba quando voltarmos, e Jaja vai plantar hibiscos roxos também, e eu vou plantas ixoras para podermos sugar o suco das flores" (ADICHIE, 2011, p. 321)

Além de um percurso imagético com as cores e flores na narrativa formando uma analogia à progressão da consciência e ação das personagens femininas, Adichie também insere uma construção sonora que mantém o mesmo percurso na analogia da transgressão. As músicas que surgem nos espaços narrativos partem de uma presença de cantos religiosos católicos para uma intercalação com os cantos em igbo, protagonizados pelo padre Amadi e os membros da família de Ifeoma nos momentos de oração e se envolvem com as músicas de artistas nigerianos(as) conscientes e ativistas, como afirma Amaka, como Fela Kuti, Osadebe e Onyeka. Kambili, no memento catártico de retorno para o local onde se libertou, a cidade de sua tia, retoma a presença do som em alinhamento com o espaço para seu entendimento subjetivo:

Enquanto voltávamos a Enugu, eu ri alto, mais alto que o canto vigoroso de Fela. Ri porque as ruas sem asfalto de Nsuka sujam os carros de poeira durante o harmattan e de lama grudenta durante a estação das chuvas. [...] Porque Nsuka pode libertar algo no fundo de sua barriga que sobe até a garganta da gente e sai sob a forma de uma canção sobre a liberdade. E sob a forma de riso (ADICHIE, 2011, p. 313).

A maternidade em Hibisco roxo fecha seu ciclo apontando para um renascimento, um novo ciclo de vivência que foi impulsionado por esta categoria na vida, sobretudo, de Beatrice e Ifeoma. Diferentemente da tia da protagonista, Beatrice não é uma personagem apresentada pela narradora, seja por características físicas ou psicológicas. Essa personagem atua no romance paradoxalmente de forma contínua e com traços ocultos de participação. O silêncio que lhe acompanha passa do campo sonoro da linguagem, com a não-verbalização de muitos sentimentos e revoltas, para o campo da ação propriamente dita, agindo no assassinato do seu marido com o envenenamento paulatino dentro dos chás que lhe era servido. Candido (1987) aponta como características da personagem no romance, duas formas principais tratadas na teoria literária:

1) como seres íntegros e facilmente delimitáveis, marcados duma vez por todas com certos traços que os caracterizam; 2) como seres complicados, que não se esgotam nos traços característicos, mas têm certos poços profundos, de onde pode jorrar a cada instante o desconhecido e o mistério (p. 6o). 
Beatrice pode ser vista, então, como uma personagem que é preenchida (e preenche) do desconhecido e do mistério diante da trama vivida. Sua ação ao final do romance participa como um paradigma da maternidade e da subversão que essa se apropria para assumir um outro papel enquanto sujeito feminino. Por isso, a protagonista do romance, assim como sua prima Amaka, anunciam um novo ciclo no entendimento com a suas relações com o corpo, fertilidade, casamento e autonomia, no campo social e subjetivo.

\section{Últimas Considerações}

Com a análise do romance em tela, observamos as desconstruções de estereótipos, introduzindo uma outra visão epistêmica da maternidade pela narrativa. É importante também ressaltar a complexidade que um sistema de organização social, cultural e política pode abarcar, saindo de uma visão simplista e dicotômica que coloca tanto o matriarcado quanto o sistema patriarcal como estruturas fixas e uniformes. Nessas organizações, que caminham com o tempo até a contemporaneidade, é direcionado aqui o olhar para os indivíduos e o debate de uma crítica que dialogue com outras existências de territórios não-africanos, mas que ressalve suas singularidades. A perspectiva de luta de mulheres pela libertação de opressões foi trazida aqui, sobretudo os discursos de questionamentos proferidos pela voz das personagens femininas no romance de Chimamanda Adichie.

A literatura de autoria feminina que ocupou este artigo nos proporciona um olhar, também, crítico-teórico sobre tais escritos, pois a literatura atua como um espaço de reflexão para a voz no feminino, ficcionalizado na narrativa, mas que apresenta a enunciação como uma categoria de reorganização de poder e do discurso. Diante da observação de uma recorrência da maternidade como uma categoria que recai sobre o feminino, pensando a categoria do corpo e papeis sociais, e que também se identifica como uma força singular de transformação positiva por poder recriar uma nação com a geração e com o maternar consciente e ativo; temos estas proposições nos escritos de autoria feminina que participaram de um diálogo com a escritora Chimamanda Adichie, o qual nos fez observar que maternidade, além de ser um status de poder da mulher, é principalmente um ato político de empoderamento social que se reverbera em várias possiblidades de fortalecimento de um discurso humanitarista emergencial.

\section{Referências}

ADICHIE, Chimamanda Ngozi. Hibisco roxo. Tradução Julia Romeu. São Paulo: Companhia das Letras, 2011. 
Sejamos Todos Feministas. Tradução Christina Baum. 1a ed. São Paulo: Companhia das Letras, 2015.

AMADIUME, Ifi. Male Daughters, female husbands: gender and sex in african society. London: Zed Books, 1987, 2015.

APPIAH, Kwame Anthony. Na casa de meu pai: a África na filosofia da cultura. Trad. Vera Ribeiro. Rio de Janeiro: Contraponto, 1997.

BAKARE-YUSUF, Bibi. Além do determinismo: A fenomenologia da existência feminina Africana. Tradução Aline Matos da Rocha e Emival Ramos. Feminist Africa, Issue 2, 2003.

CANDIDO, Antônio. A personagem da ficção. São Paulo: Perspectiva, 1972.

CHUKWUMA, Helen. Women's Quest For Rights: African Feminist Theory In Fiction. Forum on Public Policy. 2006.

FRY, Northrop. Anatomia da crítica. Trad. Péricles Eugênio da Silva Ramos. São Paulo: Cultrix, 1957.

MAMA, Amina. "Las fuentes históricas nos dicen que incluso las mujeres blancas han mirado siempre hacia África para encontrar alternativas a su subordinación". [entrevista]. In: Africana: Aportaciones para la descolonización del feminismo. Colección Pescando husmeos no 10. Ed. Cozebap, Barcelona, 2013.

McCLINTOCK, Anne. Couro Imperial: raça, gênero e sexualidade no embate colonial. Campinas: Editora da UNICAMP, 2010.

MENDILOW, A. A. O tempo e o romance. Porto Alegre: Editora Globo S. A., 1972.

O'BRIEN, Mary. The Dialectics of Reproduction. In: O'REILLY, Andrea. Maternal Theory: Essential Readings. Canada: Demeter Press, 2007, não paginado.

O’REILlY, Andrea. Maternal Theory: Essential Readings. Canada: Demeter Press, 2007, não paginado.

. Feminist Mothering. In: O'REILLY, Andrea. Maternal Theory: Essential Readings. Canada: Demeter Press, 2007, não paginado.

Recebido em 21/03/2021.

Aceito em 03/06/2021. 